\title{
Motivation in Periodontal Therapy: Assessment Using Novel Dental Treatment Motivation Scale (DTMS)
}

\author{
Sripriya Nagarajan ${ }^{1 *}$, Chakravarthy Reddy ${ }^{2}$ and Rampalli Viswa Chandra ${ }^{2}$ \\ ${ }^{1}$ Department of Public Health Dentistry, SVS Institute of Dental Sciences, Mahabubnagar, Telangana, India \\ ${ }^{2}$ Department of Periodontics, SVS Institute of Dental Sciences, Mahabubnagar, Telangana, India
}

*Corresponding author:Sripriya Nagarajan, MDS, Associate Professor, Department of Public Health Dentistry, SVS Institute of Dental Sciences, Mahabubnagar, Telangana, India, Tel: 91-8542-271515; E-mail: sripriya_vc@yahoo.co.in

Rec Date: Nov 08, 2014; Acc Date: Nov 24, 2014; Pub Date: Nov 29, 2014

Copyright:@ 2014 Nagarajan S, et al., This is an open-access article distributed under the terms of the Creative Commons Attribution License, which permits unrestricted use, distribution, and reproduction in any medium, provided the original author and source are credited.

\author{
Abstract \\ Purpose: To assess motivation in patients undergoing periodontal treatment by using the novel Dental Treatment \\ Motivation Scale (DTMS).
}

Materials and Methods: The study is a questionnaire study, consisting of 15 questions using a motivation scale to test what factors motivate the patient to undergo periodontal therapy. 212 patients attending the Department Of Periodontics for periodontal therapy in the month of May, 2014 were evaluated through the questionnaire.

Results: All patients showed high degree of motivation for undergoing treatment. Intrinsic motivation scored higher than extrinsic motivation.

Conclusions: Motivation plays an important role in treatment seeking behavior. Dentists can play a vital role in motivating and counseling patients to undergo periodontal therapy.

Keywords: Motivation scale; Periodontaltreatment; DTMS

\section{Introduction}

Motivation has been shown to have roots in physiological, behavioral, cognitive and social areas and is rooted in a basic impulse to optimize well being, minimize physical pain and maximize pleasure [1]. Motivation also plays an important role in perceived dental competence and treatment seeking behavior among dental patients. Different theories and models such as the push-pull model [2] and the self-determination theory [1] have sought to explain the various intrinsic and extrinsic influences affecting the patients' motivation to undergo or refuse treatment.

Chronic periodontitis is a multifactorial disease. Along with microorganisms which are responsible for the initiation of the inflammatory reaction leading to subsequent periodontal tissue loss, several other local and systemic factors have been shown to play important modifying roles in enhancing the inflammatory or destructive effects of microorganisms [3].

A range of host-related factors which include, but are not limited to, smoking, poorly controlled diabetes, poor oral hygiene, extent and severity of alveolar bone loss, positive family history, proportion of pocket probing depths $>5 \mathrm{~mm}$, age, gender, and gingival bleeding can influence the onset, clinical presentation, and rate of periodontal disease progression. In such a disease with multifactorial etiologies and complex treatment strategies $[3,4]$, very few studies have focused on the role of motivation in dental treatment seeking behavior.

The role of motivation in dental care is thought to play a major role in influencing dental health behavior [5]. A previous study [6] which reviewed the behavior self-regulation model in context of self-care showed that patient motivation was influenced by dental professional and the incentives and rewards offered during the treatment phase. Halvari et al. [7] developed a self regulation questionnaire for dental treatment which showed that autonomous motivation for dental competence were positively associated with oral self care behavior and dental clinic attendance.

The study of Pac et al. [8] assessed motivation among periodontal patients using the zychlinscy scale and found it to be a reliable tool. It also assessed the correlation between the scale and clinical parameters and found that patients with greater motivation had better oral hygiene.

However, the tool does not assess the extrinsic and intrinsic influences that motivate the patient to agree for a treatment. Gao et al. [4] assessed the effect of motivational interviewing (MI) in improving oral health through a systematic review and found that four studies reported positive effects of MI on oral health outcomes whereas another four showed null effect. The study emphasized on the need for further studies with methodological rigor for a better understanding of the roles of MI in dental practice.

There is a definite paucity in studies evaluating the role of motivation in treatment seeking behavior of periodontal patients. The research hypothesis of this study is that is no significant relationship between motivation and treatment seeking behavior among periodontal patients. Hence this study is an attempt to assess the role of motivation in periodontal care by using the Dental Treatment Motivation Scale (DTMS) which in itself is a shortened version of a self-regulation questionnaire for dental treatment [7] subsequently 
modified based on a questionnaire used for assessing motivation in Type-2 diabetic patients $[9,10]$.

\section{Patients and Methods}

\section{Study population}

The sample population included 217 patients attending the Department of Periodontology, SVS Institute of Dental Sciences, Mahabubnagar, India, for periodontal therapy in the month of May, 2014. Subjects were aged between 18-55 years. Three incomplete questionnaires were discarded and two subjects who gave motivational responses were excluded from the study limiting the final sample size to 212 .

\section{Sample size}

The sample size was determined as 217 with confidence level set at $95 \%$ with a confidence interval of 5 for a population of 500 based on monthly OPD records. A random sampling method using a computergenerated table was used for patient selection. Patients were diagnosed as having chronic periodontitis when there was a clinical evidence of probing depth or CAL $\geq 5 \mathrm{~mm}$ in at least 2 sites in each of the 4 quadrants with $30 \%$ of the dentition showing BOP at baseline examination.

\section{Ethical aspects}

Before the data collection the project was approved by the ethical review board (SVS \#306009). Subjects who agreed to participate signed an informed consent

\section{Instrument}

The instrument used for data collection consisted of sociodemographic questions in addition to the Dental Treatment Motivation Scale (DTMS) questionnaire (Figure 1). The DTMS is a Likert scale composed of 15 items in which 7 (Q no: 1, 2, 5, 7, 10, 13 \& 15) and 8 (Q no: 3, 4, 6, 8, 9, 11, 12 \& 14) questions assess intrinsic and extrinsic motivation respectively.

The scale measures autonomous and controlled motivations to adopt a healthy attitude towards periodontal treatment. Answers are organized on a Likert scale of 1 to 5 ranging from "strongly disagree" to "strongly agree". The score of each dimension is obtained by the total sum of all answers of the items in each dimension by the total score. The study was translated into the local language. To check for the consistency the study was back translated into English by two independent bilingual dentists.

\section{Statistical analysis}

Data was analysed using a commercially available statistical software package (SPSS ver.21). Descriptive statistics and frequency distributions were analysed. Reliability analysis for internal consistency was done by using Cronbach's alpha with item deletion included to check whether the removal of item brought about a change in the reliability. The Mann-Whitney $U$ test was used to compare differences between intrinsic and extrinsic motivations. A p-value of $<0.05$ was considered statistically significant.

\section{Results}

The study population included 212 subjects attending the Department of Periodontics for treatment. Cronbach's alpha of the study questionnaire gave a value of 0.83 which is acceptable level of reliability. Most items showed a good degree of total correlation around 0.4 except question 1 (responsibility for own health and question) and question 2 (others being furious). However, item deletion showed very slight change in the reliability $(0.86)$ hence the questions were not removed (Table 1).

\begin{tabular}{|c|c|c|}
\hline Item & Corrected Item-Total Correlation & Cronbach's Alpha if Item Deleted \\
\hline Q1 & .084 & .848 \\
\hline Q2 & .048 & .851 \\
\hline Q3 & .494 & .826 \\
\hline Q4 & .511 & .825 \\
\hline Q5 & .353 & .833 \\
\hline Q6 & .301 & .835 \\
\hline Q7 & .462 & .828 \\
\hline Q8 & .289 & .836 \\
\hline$Q 9$ & .400 & .833 \\
\hline Q10 & .630 & .817 \\
\hline Q11 & .449 & .829 \\
\hline Q12 & .452 & .828 \\
\hline Q13 & .411 & .649 \\
\hline Q14 & .409 & .816 \\
\hline Q15 & .411 & .831 \\
\hline Intrinsic & .873 & .818 \\
\hline Extrinsic & .900 & .818 \\
\hline TOTAL & .999 & .818 \\
\hline
\end{tabular}

Figure 1: The questionnaire used in this study is a shortened version of a self-regulation questionnaire for dental treatment subsequently modified based on a questionnaire used for assessing motivation in Type-2 diabetic patients. It is composed of 15 items in which 7 (Q no: 1, 2, 5, 7, 10, 13 \& 15) and 8 (Q no: 3, 4, 6, 8, 9, $11,12 \& 14)$ questions assess intrinsic and extrinsic motivation respectively.

\begin{tabular}{|l|l|l|}
\hline \multicolumn{3}{|c|}{ Reliability Statistics } \\
\hline $\begin{array}{l}\text { Cronbach's } \\
\text { Alpha }\end{array}$ & $\begin{array}{l}\text { Cronbach's Alpha Based on Standardized } \\
\text { Items }\end{array}$ & $\begin{array}{l}\text { No. of } \\
\text { Items }\end{array}$ \\
\hline 0.837 & 0.869 & 18 \\
\hline
\end{tabular}

Table 1: Reliability Analysis for the Questionnaire using the Cronbach's alpha reliability coefficient

\section{Questionnaire data evaluation}

Table 2 shows the distribution of subjects based on gender and age. $64 \%$ of subjects were females and most of the subjects were in the age group of 36-45 years. Analysis of the responses to the questionnaire indicated that items high degree of treatment motivation was seen for items 1, 5 and 12 ("responsibility for own health", "it is the best thing for my oral health", "it improves social acceptability") whereas items 2, $6,7,8$ and 14 showed stronger disagreement "others would be furious", "pressure from others", "guilt factor", "others to approve", "others to see I can do it"). The subjects showed high intrinsic, extrinsic and total motivation values (Table 3). A comparison of the intrinsic and extrinsic motivation scores (Table 4) showed a highly significant difference with intrinsic motivation being higher than the extrinsic motivation $(\mathrm{p}<0.001)$. 
Page 3 of 4

\section{Discussion}

The Dental Treatment Motivation Scale is a modification of Treatment Self-Regulation Questionnaire (TSRQ) [9]. The TSRQ is a set of questionnaires concerning why a subject would engage in healthy behavior, solicit treatment for some disease, try to change an unhealthy behavior, follow a treatment regimen or engage in some other health related behavior. All questionnaires have the same purpose; which is to assess the degree to which one's motivation for a particular behavior is autonomous or self-determined.

The TSRQ was utilized for assessing a number of outcomes like "behaving in a healthy way" [11], "motivation for psychotherapy" [12] and "motivation for alcohol treatment" [13]. The present study is an adaptation of TSRQ used in type 2 diabetic patients for assessing the role of motivation in periodontal treatment seeking behavior.

\begin{tabular}{|l|l|l|l|l|l|}
\hline & $\mathbf{1 5 - 2 5 y e a r s}$ & $\mathbf{2 6 - 3 5 y e a r s}$ & $\mathbf{3 6 - 4 5 y e a r s}$ & $\mathbf{4 6 - 5 5 y e a r s}$ & Total \\
\hline Males & 0 & 22 & 36 & 18 & $76(36 \%)$ \\
Females & 35 & 31 & 30 & 41 & $136(64 \%)$ \\
\hline Total & 35 & 53 & 66 & 59 & $\mathbf{2 1 2 ( 1 0 0 \% )}$ \\
\hline
\end{tabular}

Table 2: Distribution of subjects based on age and gender

\begin{tabular}{|c|c|c|}
\hline Treatment motivation items & Mean & SD \\
\hline 1. I feel that I want to take responsibility for my own health & 4.03 & 1.317 \\
\hline 2. Others would be furious if I did not do it & 2 & 1.093 \\
\hline 3. I have carefully thought about it and believe it is very important for many aspects of my life & 3.87 & 1.477 \\
\hline 4. My dentist asked me to do so & 3.36 & 1.399 \\
\hline 5. I personally believe that it is the best thing for my dental health & 4.28 & 0.971 \\
\hline 6. I feel pressure from others to do so & 1.48 & 0.806 \\
\hline 7. I would feel guilty if I didn't do it & 2.34 & 1.508 \\
\hline 8. I want others to approve of me & 2.37 & 1.146 \\
\hline 9. I want the dentist to think I am a good patient & 2.91 & 1.555 \\
\hline 10. It is easier to do it rather than to think about it & 3.1 & 1.652 \\
\hline 11. I don't want others to be disappointed in me & 2.2 & 0.886 \\
\hline 12.It improves my social acceptability & 4.21 & 1.166 \\
\hline 13. I would feel bad about myself if I didn't do it & 2.74 & 1.358 \\
\hline 14. I want others to see I can do it & 2.17 & 1.106 \\
\hline 15. It feels good to keep my oral cavity as clean as possible & 3.92 & 0.904 \\
\hline Intrinsic motivation & 3.2 & 0.674 \\
\hline Extrinsic motivation & 2.81 & 0.67 \\
\hline Total motivation & 2.91 & 0.567 \\
\hline
\end{tabular}

Table 3: Average values and dispersion of answers to items that evaluate treatment motivation

\begin{tabular}{|l|l|l|l|}
\hline Item & Mean rank & Mann Whitney U & p-value \\
\cline { 1 - 2 } Intrinsic motivation & 238.12 & \multirow{2}{*}{17040} & $0.0001 \ddagger$ \\
\cline { 1 - 2 } Extrinsic motivation & 186.88 & & \\
\cline { 1 - 2 } Analysis using Mann Whitney U test, $p<0.000$ highly significant \\
\hline
\end{tabular}

Table 4: Comparison of scores between intrinsic and extrinsic motivation

The questionnaire showed a good degree of reliability making it a valid tool for periodontal treatment planning. The results of the study showed that the subjects showed high motivation towards periodontal treatment thus rejecting the null hypothesis and accepting the alternate hypothesis. The intrinsic motivation component scored more than the extrinsic component. Motivation is an important component for treatment seeking behavior.

According to the health belief model [14] and as a part of intrinsic motivation, a person will take a health-related action only when the recommended action can help avoid a detrimental health condition. In the present study though the subjects relied on both intrinsic and extrinsic motivation factors for treatment seeking behavior, the intrinsic motivation, which is the patients belief that he is responsible for his own health scored higher. The results are similar to the study done by Oruba et al. [15] who showed the more motivated the patient was the better was his oral health. 
The lowest treatment motivation scores were given for "pressure from others" and "others being furious for not undergoing treatment" which showed that though extrinsic variables are important for treatment seeking behavior, a subjects own belief and responsibility towards his or her health will ultimately contribute to increased motivation. The results are in conformity with a previous study [5] which showed intrinsic motivation played a major role in health related behavior.

The extrinsic variables that play an important role in treatment seeking behavior are pressure, professional advice, social acceptability and opinion of others. In the present study the extrinsic factor that scored high on patients motivation scale was social acceptability. The other factors included the dentist advice and appreciation of the dentists. This is similar to the study done by Ramsey [6] and Halvari et al. [7] where professional advice plays an important role in treatment seeking behavior.The study showed the motivation scores were similar among males and females and across different age groups.

According to the self-determination theory (SDT) [9], subjects with internal perceived locus of causality (PLOC) feel they are the initiators and sustainers of their own actions whereas subjects with external perceived locus of causality (PLOC) see forces outside the self as initiating, pressuring, or coercing one's action. The present study showed a strong internal PLOC than external PLOC.

Periodontitis is a condition where the overall treatment plan can be daunting; a subject with periodontitis must show considerable motivation in all phases of the treatment plan. Studies have shown that insufficient motivation may only result in short-term successes in periodontitis subjects $[3,16]$. In periodontics, there is now a tremendous onus on individually tailored periodontal treatment programs based on the patient behaviour patterns [17]. At the same time, newer motivation scales are also being evaluated and adopted primarily for the evaluation of motivation in periodontitis patients [15].

Overall the study showed a high degree of motivation for treatment seeking behavior facilitated by both intrinsic and extrinsic factors.Internalization and integration is a process by which extrinsically motivated behavior can become self-determined $[18,19]$. A number of extrinsic factors have also played a small role in motivating treatment related behavior in this study such as the professional help, appreciation and social acceptability [20]. Dentists can play a major role by facilitating treatment seeking behavior through professional advice and reinforcements and thus help in integrating and internalizing extrinsic behavior to an intrinsic motivation. A subjects' dentist, his peers and his family can play an important role in bringing about a positive health related behavior.

To conclude, the study tested the Dental Treatment Motivation Scale (DTMS) to assess motivation for seeking periodontal therapy. The scale showed good consistency as well as validity and can be used for assessing motivations for other dental treatments as well. The limitation of this study is that the sample size was small and correlation with the actual clinical condition was not carried out. More longitudinal studies with larger samples in a multicentric setting are warranted to further explore the feasibility and acceptability of DTMS.

\section{References}

1. Ryan RM, Deci EL (2000) Intrinsic and Extrinsic Motivations: Classic Definitions and New Directions. Contemp Educ Psychol 25: 54-67.
2. Dann GMS (1981) Tourist motivation: an appraisal. Ann Tour Res 8:187-219.

3. Brand VS, Bray KK, MacNeill S, Catley D, Williams K (2013) Impact of single-session motivational interviewing on clinical outcomes following periodontal maintenance therapy. Int J Dent Hyg 11: 134-141.

4. Gao X, Lo EC, Kot SC, Chan KC (2014) Motivational interviewing in improving oral health: a systematic review of randomized controlled trials. J Periodontol 85: 426-437.

5. Syrjälä AM, Kneckt MC, Knuuttila ML (1999) Dental self-efficacy as a determinant to oral health behaviour, oral hygiene and HbAlc level among diabetic patients. J ClinPeriodontol 26: 616-621.

6. Ramsay DS (2000) Patient compliance with oral hygiene regimens: a behavioural self-regulation analysis with implications for technology. Int Dent J Suppl Creating A Successful: 304-311.

7. Halvari AEM, Halvari H, Bjørnebekk G, Deci EL (2010) Motivation and anxiety for dental treatment: Testing a self-determination theory model of oral self-care behavior and dental clinic attendance. MotivEmot 34: 15-33.

8. Pac A, Oruba Z, Olszewska-Czy I, Chomyszyn-Gajewska M (2014) The significance of motivation in periodontal treatment: validity and reliability of the motivation assessment scale among patients undergoing periodontal treatment. Community Dent Health 31: 53-56.

9. Ryan RM, Connell JP (1989) Perceived locus of causality and internalization: examining reasons for acting in two domains. J PersSocPsychol 57: 749-761.

10. Apóstolo JL, Viveiros CS, Nunes HI, Domingues HR (2007) Illness uncertainty and treatment motivation in type 2 diabetes patients. Rev Lat Am Enfermagem 15: 575-582.

11. Williams GC, Cox EM, Kouides R, Deci EL (1999) Presenting the facts about smoking to adolescents: effects of an autonomy-supportive style. Arch PediatrAdolesc Med 153: 959-964.

12. Pelletier LG, Tuson KM, Haddad NK (1997) Client Motivation for Therapy Scale: a measure of intrinsic motivation, extrinsic motivation, and amotivation for therapy. J Pers Assess 68: 414-435.

13. Ryan RM, Plant RW, O'Malley S (1995) Initial motivations for alcohol treatment: Relations with patient characteristics, treatment involvement and dropout. Addic Behav 20: 279-297.

14. Becker MH, Radius SM, Rosenstock IM, Drachman RH, Schuberth KC, et al. (1978) Compliance with a medical regimen for asthma: a test of the health belief model. Public Health Rep 93: 268-277.

15. Oruba Z, Pac A, Olszewska-Czy I, Chomyszyn-Gajewska M (2014) The significance of motivation in periodontal treatment: the influence of adult patients' motivation on the clinical periodontal status. Community Dent Health 31: 183-187.

16. de Carvalho VF, Okuda OS, Bernardo CC, Pannuti CM, Georgetti MA, et al. (2010) Compliance improvement in periodontal maintenance. J Appl Oral Sci 18: 215-219.

17. Jönsson B, Ohrn K, Lindberg P, Oscarson N (2012) Cost-effectiveness of an individually tailored oral health educational programme based on cognitive behavioural strategies in non-surgical periodontal treatment. J Clin Periodontol 39: 659-665.

18. Deci EL, Eghrari H, Patrick BC, Leone DR (1994) Facilitating internalization: the self-determination theory perspective. J Pers 62: 119-142.

19. Ryan RM (1995) Psychological needs and the facilitation of integrative processes. J Pers 63: 397-427.

20. Yu CH, Stacey D, Sale J, Hall S, Kaplan DM, et al. (2014) Designing and evaluating an interprofessional shared decision-making and goal-setting decision aid for patients with diabetes in clinical care--systematic decision aid development and study protocol. Implement Sci 9: 16. 